\title{
Internet of Things based Heart Beat Monitoring System
}

\author{
Karhale Deepali B, Thorat Suryakant B
}

\begin{abstract}
Healthcare is an area that is rapidly developing in technology and services. A recent development in this area is remote monitoring of patients which has many advantages in a fast aging world population with increasing health complications. The Internet of Thongs (IOT) plays important role to monitor patient health remotely. With help of Arduino Microcontroller, Wifi module and sensors this can be possible. Sensors for monitoring essential vital signs such as electrocardiogram reading, heart rate, respiration rate, blood pressure, temperature, blood glucose levels and neural system activity are available today. Humans are facing a retardant of surprising death because of varied sickness that is because lack of medical aid to the patients at right time. Most of death happened due to right treatment at right time. With the help of technology only now it can be possible to minimize such death. The fetched data through sensors which is attached to human body can be retrieved and store on ThingSpeak cloud is used here. The Doctors can view patient's medical records remotely, recommend or prescribe drug, request for ambulance or visit patient based on data being sent from the monitoring system [13].
\end{abstract}

Keywords: ThingSpeak, WHO, RTMS, PMS, ECG.

\section{INTRODUCTION}

Prosperity is one of the overall most challenging aspect for humanity [1]. As demonstrated by the constitutions of World Health Organization (WHO) the most significant doable standard of prosperity is a head straightforwardly for an individual [2]. Strong individuals lead to confirm their lifetime pay and along these lines to increase in complete national yield and in control salaries. Strong individuals moreover decline pressure on the starting at now overwhelmed crisis facilities, focuses, and therapeutic specialists and lessen remaining weight on the open prosperity frameworks, philanthropies, and authoritative (or non-managerial) affiliations. To keep individuals strong an effective and quickly accessible current restorative administrations structure is a fundamental. A progressive health care system need to provide higher tending services to folks at any time and from anywhere in an economic and patient friendly manner. Currently, the tending system is

Revised Manuscript Received on December 30, 2019.

* Correspondence Author

Mrs. Karhale Deepali B, Reasearch Scholar, School of Computational Sciences, at S. R. T. M. University, Nanded. Maharashtra, India. Email: dbkarhale18@gmail.com

Dr. Thorat Suryakant B, Director SSBES'S ITM College, Nanded. Maharashtra, India. Email: suryakant thorat@yahoo.com

(C) The Authors. Published by Blue Eyes Intelligence Engineering and Sciences Publication (BEIESP). This is an open access article under the CC BY-NC-ND license (http://creativecommons.org/licenses/by-nc-nd/4.0/) undergoing a cultural shift from a regular approach to a progressive patient targeted approach. Among the traditional approach the tending professionals play the key role. They need to travel to the patients for necessary designation and advising. There unit of measurement two basic problems associated with this approach. Firstly, the tending professionals ought to get on web site of the patient all the time and second, the patient remains admitted terribly\} very hospital, wired to aspect medicine instruments, for associate degree quantity. By encapsulating the benefits of up thus far bioinstrumentation, computers, and telecommunication technologies a recent PMS ought to acquire, record, display, and transmit the physiological data from the patient body to a distant location at any time. For heaps of economical, timely, Associate in nursing emergency treatment the PMS need to even be incorporated with Associate in nursing alarm. In order to alert the patient still because the health care service providers the PMS mustn't solely monitor and analyze the important patient's information however it ought to additionally send alarming messages just in case the monitored information go outside their normal ranges. Hence, a lively info system should be related to the PMS. Most of the planned PMSs are centralized in a very sense that everyone patients' information are hold on in a very single server. By exploitation necessary microcode associate degreed software system the server is connected to an open communication network via TCP/IP protocol. Thus a patient can be monitored from a remote location. Existing and widespread mobile phone networks can assist in this regard. Considerably in the wake of interfacing these frameworks to a specific patient, a paramedical partner need to constantly screen and note down all the indispensable parameters of a predefined understanding by monitoring the entirety of his/her records physically. Upholding such a technique is blunder inclined and may prompt catastrophe on account of a human mistake [3].Health Monitoring System Benefits

Permits sending data from patients to health professionals in real time. The fundamental favorable position of remote quiet checking or homecare telehealth, is that it allows a patient to utilize a versatile medicinal gadget to accomplish routine tests and send test results to a specialist progressively without the need of visiting a therapeutic establishment. This favorable position is of exorbitant significance for individuals with long haul ailments, who need to speak with medicinal services experts all the more regularly. Homecare telehealth empowers simple and quick correspondence among specialists and patients experiencing rest issue, mental, cardiovascular, and respiratory and different maladies.

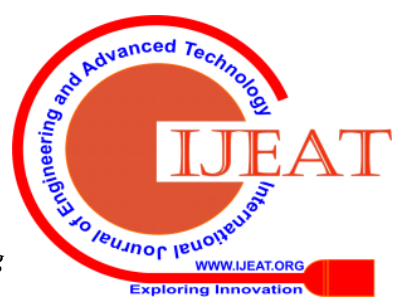


Specialists can exhort wiped out individuals online with no compelling reason to hang tight for the arrangement date.

Recovers patients' lifestyle. Incorporating RPM in chronic disease management will suggestively improve an individual's quality of life. Due to rate, inveterately unwell individuals will devote longer reception with their families instead of at hospitals. A monitor is additionally able to inform patients regarding essential deterioration of health once they ought to apply for emergency facilitate as before long as doable.

More Availability. This system permits doctors to achieve out to potential patients. Whereas many of us can't stand aiming to clinics or, sure reasons, can't afford visiting a doctor, this technique can bring free consultation with a medico right to their homes. However medical establishments can gain a lot of visitors while not congestion facilities.

Saves money. Patients will save significantly due to this system. With home telehealth, it's not necessary to travel to a clinic for medication or raise your MD regarding tests results. Besides, because of the decreasing range of unnecessary hospital visits, medical establishments abate crowded and may quicker admit patients WHO would like AN emergency facilitate [5].

\section{LITERATURE REVIEW}

In the past existing strategy PC gadgets utilized as information procurement (DAQ) frameworks we can gather imperative data about the old patients remotely. Existed framework which screens temperature and heartbeat pace of various patients and prompt move is made utilizing Bluetooth innovation. The Mobile Hub has numerous appealing highlights less expensive value, compact, area mindfulness, inbuilt touch screen, anyway on the opposite side it has likewise huge constraints contrasted with a full PC equipment like restricted CPU control, memory, stockpiling size and outside interface association support, The Mobile Hub is focusing on various functionalities contrasted with the Home Hub arrangement because of the littler screen size and less equipment interfaces, and it can expand the ease of use with extra extraordinary highlights, for example, versatility, area mindfulness and little size. Portable Hub programming is skilled to run practically all Bluetooth empowered and Android based Smartphone. In an unexpected frenzy circumstance an alert can be initiated physically (by the patient) or naturally (by for example the accelerometer) with the cell phone. At the point when an alert sign started the focal dispatcher can gain area data (in light of GSM/GPRS cell data) promptly [7].

The investigation of a Wireless multimedia sensor Network (WMSN) and often ness Identification (RFID) primarily based u-Healthcare framework. The framework [8] is provided for observant the patient's meditative standing by utilizing RFID body sensing element and remotely transmits the restorative info to a close-by digital computer (WMSN passage) before transmittal it to the focal information server. Thanks to the patient's developments, WMSN hub's developments are designed with the utility of the Mobile IPv6. Patients are often afraid if there ought to arise an event of crisis through their wearable widget and might likewise get messages with their Smartphone's. The projected framework is planned [9] to determine and screen important physiological data of a patient therefore on exactly portray the standing of her or his wellbeing and eudaemonia projected a framework is meant to quantify and screen important physiological data of a patient therefore on exactly depict the standing of her or his welfare and eudaemonia. The patient's temperature, heart beat rate, muscles, pulse, blood sugar level, and electrocardiogram data area unit checked, shown, and place away by their framework. To ensure unwavering quality and exactness the planned framework has been field tried. The take a look at outcomes show that their framework will gauge the patient's physiological data with a high exactitude. Planned framework contains [10] the set up and execution with subsystems. information is distributed by suggests that of information processing to a information server containing clinical data, which may be gotten to on the advanced cell and may likewise be imparted to the doctor once ever to seem for healthful exhortation when needed. 2 remote conventions were examined: a Bluetooth (IEEE 802.15.1) specially appointed system and a LAN (IEEE 802.11) impromptu organize. To do intrinsically, 2 subsystems were planned: a detector framework and a presentation framework. The detector framework includes of 2 thermometers and an overseas transmitter/beneficiary. The data are sent to the presentation framework remotely. The showcase includes of an overseas transmitter/beneficiary associate degreed an iOS cellular phone. The outcomes regarding the adequacy and usefulness of the planned framework and therefore the change of integrity with a meter are introduced. The observant framework has the capability to screen physiological parameters from varied patient bodies. In their planned framework [11], a helper hub has joined on persistent body to collect all of the sign from the remote sensors and sends them to the bottom station. The connected sensing elements on patient's structure a foreign body sensor organize (WBSN) and that they will find the heartbeat, circulatory strain, etc. This framework will distinguish the abnormal conditions, issue associate degree awake to the patient and send a SMS/E-mail to the doctor. Planned and created internal heat level estimation device[12] that may be seen by the specialist increasingly even as history data through net with a caution/sign if there ought to arise an occasion of anomalies. The temperature sensors can send the readings to a microcontroller utilizing Zigbee remote correspondence. To send the constant data to eudaemonia observant information, remote native space Network (WLAN) has been utilized. Arduino with local area network protect captivated with IEEE 802.11 normal has been utilized for this reason. Take a look at results from a gathering of willful shows the continual temperature studying effectively discovered regionally (at home) and remotely (at specialist's PC).

\section{PROBLEM STATEMENT}

One of the total well known open concerns is human wellbeing. Whatever else becomes useless in the event that one becomes ill or dead? Hence, individuals spend a great deal of cash to hold sound wellbeing. 
Improperly, individuals consistently view that it is as past the point where it is possible to get genuine restorative consideration when things are non-invertible.

In the event that essential moves can be made in time, at that point loads of patients can be restored. Be that as it may, get to an excessive number of therapeutic hardware is badly arranged and prosperous. Pulse and internal heat level are the most fundamental ones among the most striking records of the human wellbeing, and they have the benefit of simple access. Additionally, not at all like the X-beam, the estimation of pulse and internal heat level has no impact on human wellness itself.

There are a few gadgets in the present market which can convey crude restorative estimation information to patients and specialists, yet the patients may not decipher the therapeutic estimation into important conclusion since they have minimal medicinal foundation. Then again, if crude restorative information is conveyed to the specialist, it kills a lot of time and may raise a ruckus, yet in crises time can never be squandered. It is difficult to share information over an enormous zone inside a brief period. The greater part of the items reachable in the present market have these significant hindrances with restriction in adaptability and transportability.

\section{EXISTING WORK}

The existing system works depends on remote transmission of restorative information through two handsets. The principal installed device comprises of a Raspberry Pi and Zigbee module. Raspberry Pi is associated with LCD screen, LCD $16 \times 2$, LED, bell, console and a mouse while the subsequent gadget comprises of Arduino (Mega 2560) and another Zigbee wireless module that fixed in Arduino through the ZigBee shield [6].

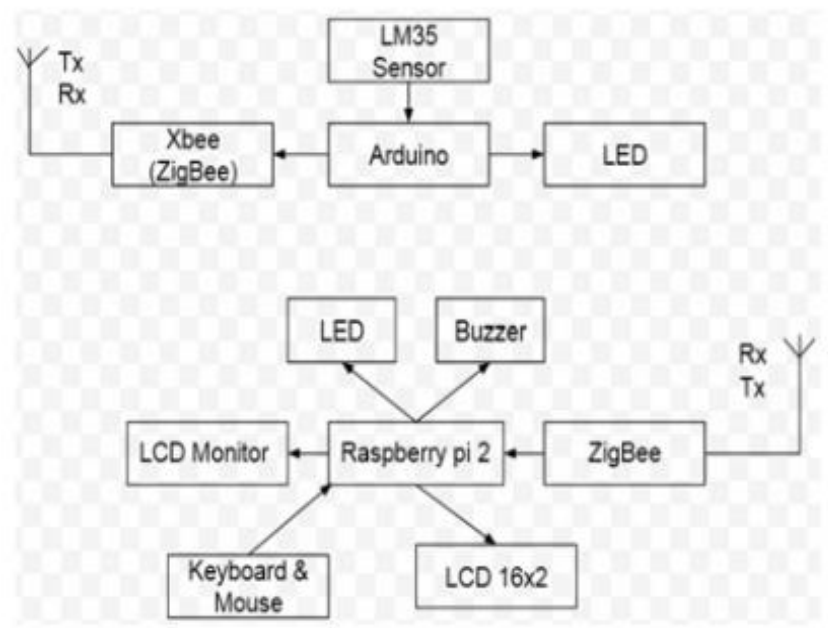

Figure 1 Figure 1 RTMS block diagram

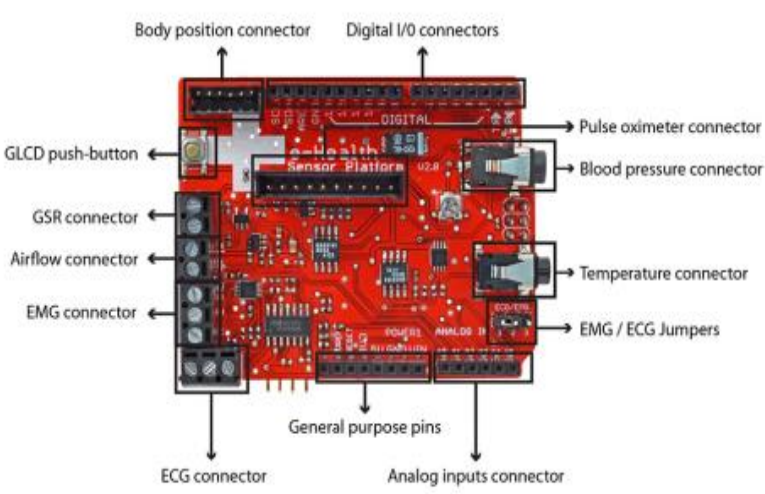

Figure 2 biometric shield

The e-health sensor module is used to connect all medical related sensors to this kit. This kit is compatible with various sensors such as SPO2, breathing sensor, glucometer EMG, ECG sensor etc. The gathered date can be transmit by using any wireless device such as Wi-Fi, Bluetooth GPRS and much more.

\section{PROPOSED SYSTEM}

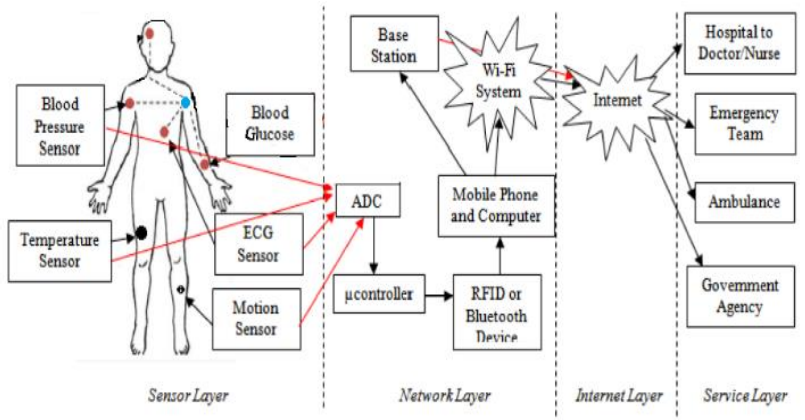

Figure 3 Proposed System

Figure 3 shows the proposed framework, different sensors are apply on human body, for example, Blood pressure, temperature sensor, ECG, movement sensor and so forth. Fixed every sensor on body as like wearable sensors. The sensors are connected to Arduino microcontroller the Arduino will get or peruse sensors esteems and however Wi-Fi arrange it will send qualities to web.

In this paper utilized the beat sensor to investigate pulse of person. It will consistently perusing estimations of heartbeat and show. The perspective on beat sensor as demonstrated as follows.

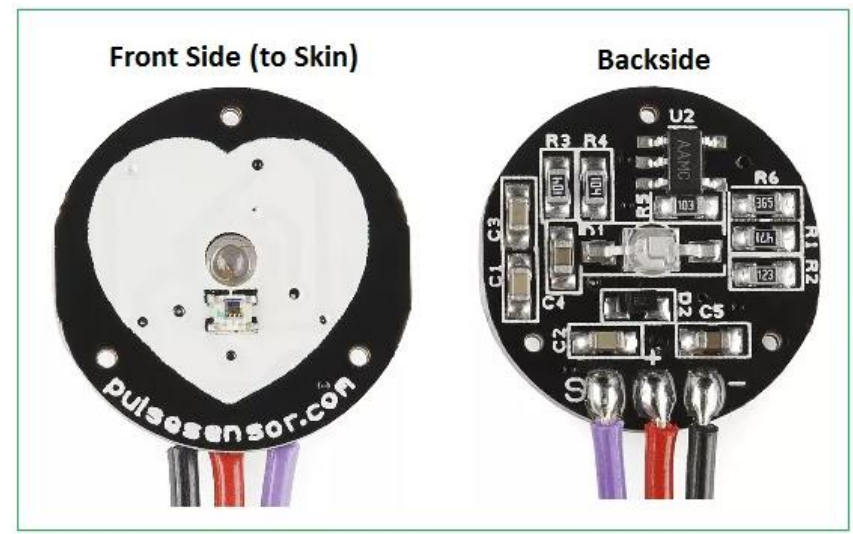

Figure 4 View of Pulse Sensor

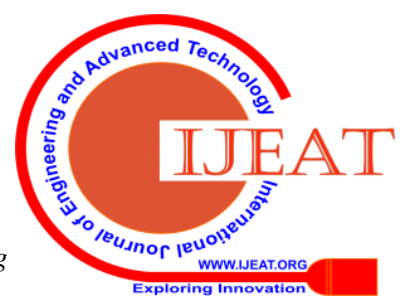


The above sensor is compatible with Arduino microcontroller. It very well may be utilized by understudies, craftsmen, competitors, creators, and game and versatile designers who need to effortlessly fuse live pulse information into their tasks. Embodiment it is a coordinated optical intensifying circuit and commotion killing circuit sensor. Clasp the Pulse Sensor to your ear cartilage or fingertip and attachment it into your Arduino, you can prepared to peruse pulse. Likewise it have an Arduino demo code that make it simple to utilize.

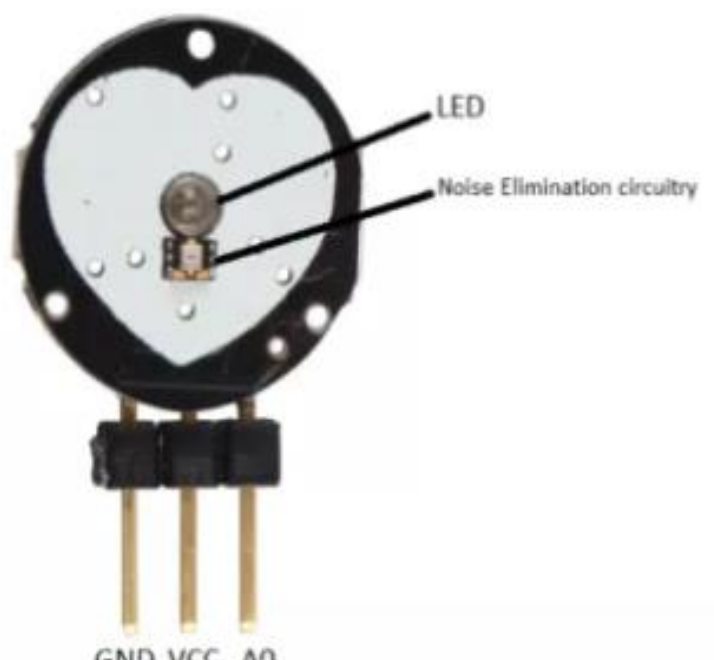

GND VCC AO

Figure 5 Pin Diagram

The beat sensor has three pins: VCC, GND and Analog Pin. There is likewise a LED in the focal point of this sensor module which helps in identifying the heartbeat. Beneath the LED, there is a clamor end hardware which should fend off the commotion from influencing the readings.

\section{Working - Pulse Sensor:}

At the point when a heartbeat happens blood is siphoned through the human body and gets crushed into the slender tissues. The volume of these narrow tissues increments because of the heartbeat. Be that as it may, in the middle of the pulses (the time between two successive pulses,) this volume inside hair like tissues diminishes. This adjustment in volume between the pulses influences the measure of light that will transmit through these tissues. This change is extremely little however we can quantify it with the assistance of Arduino. The beat sensor module has a light which helps in estimating the beat rate. At the point when we place the finger on the beat sensor, the light considered will change based the volume of blood inside the slender veins. During a heartbeat, the volume inside the hair like veins will be high. This influences the impression of light and the light reflected at the hour of a heartbeat will be less contrasted with that of the time during which there is no heartbeat (during the timeframe when there is no heartbeat or the timespan in the middle of pulses, the volume inside the fine vessels will be lesser. This will lead higher impression of light). This variety in light transmission and reflection can be acquired as a heartbeat from the yield of heartbeat sensor. This heartbeat can be then molded to quantify heartbeat and afterward customized likewise to peruse as heartbeat check.

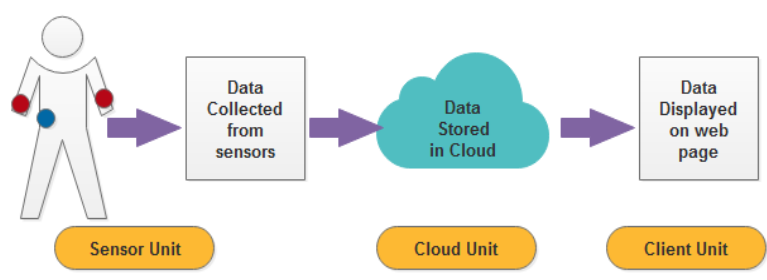

Figure 6 Flow diagram of data transfer using the system Above figure 6 depicts the data collected from sensors and it will store on cloud and stored data can be viewed by using web page.

\section{EXPERIMENT AND RESULT}

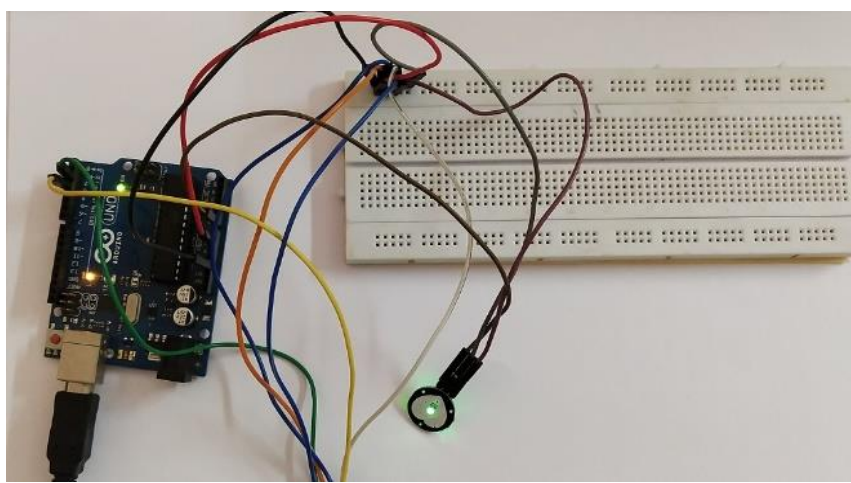

Figure 7 Sensors connected to Arduino

The figure 7 shows the connection of pulse sensor to Arduino. In this work used only one sensor.

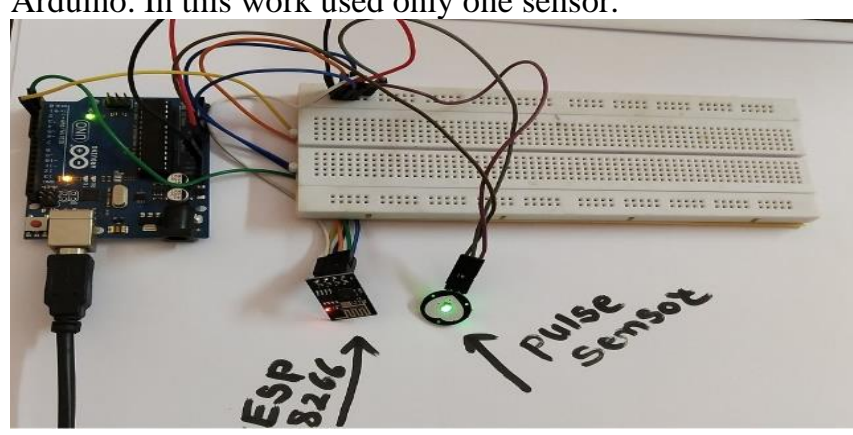

Figure 8 Pulse Sensors and ESP8266

The figure 8 shows the connection of Pulse sensor and ESP8266 the WIFI device. 


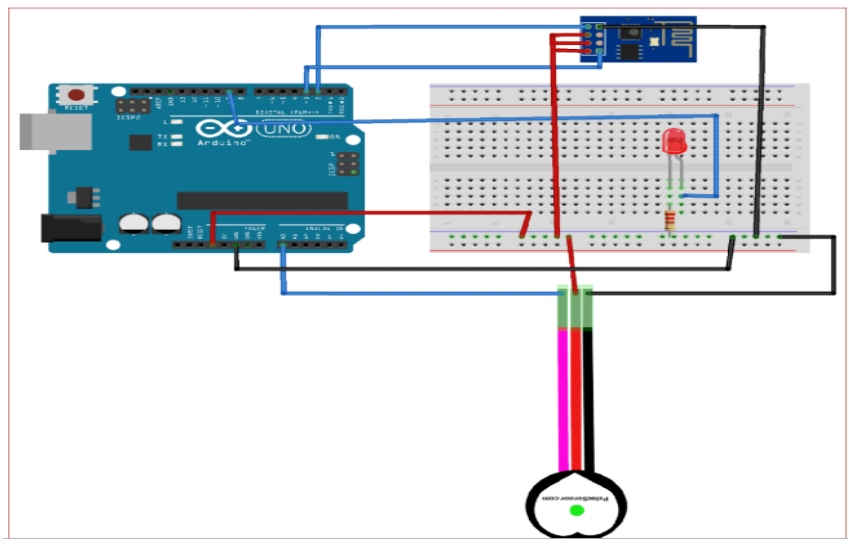

Figure 9 shows the actual connection with pin connection to Arduino.

Algorithm 1: Read value of Pulse Sensor and Send to ThingSpeak.

\section{Begin}

Function setup()

Define SSID, Password for ESP8266 and API key Baud rate $==9600 / /$ For synchronization AT commands to check ESP8266 connections

END

Function loop()

Call respective functions

If error then

Reconnect all.

End if

END

Function updateBeat() will update. send the data at the IP address //Continously data return

\section{End if}

\section{END}

Function ConnetWifi()

If connect then

Print $\mathrm{AT}+\mathrm{CWMODE}=1$

Print $\mathrm{AT}+\mathrm{CWMODE}=1$

Else

End if

Reconnet

\section{END}

Function ISR(TIMER2_COMPA_vect)

Read the sensor and will convert the output of the sensor into heart beat per minute (BPM).

Counter $=$ counter +2

\section{END}

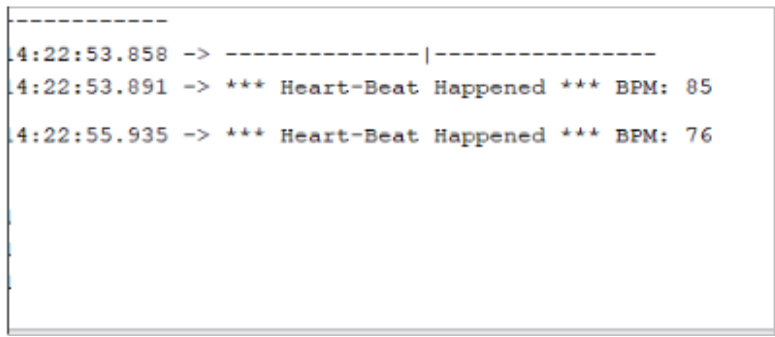

Figure 9 Serial Monitor Output if esp8266.find "Error" then

After running the code on the serial monitor of Arduino IDE above output will show. It depicts the heart rate of human.

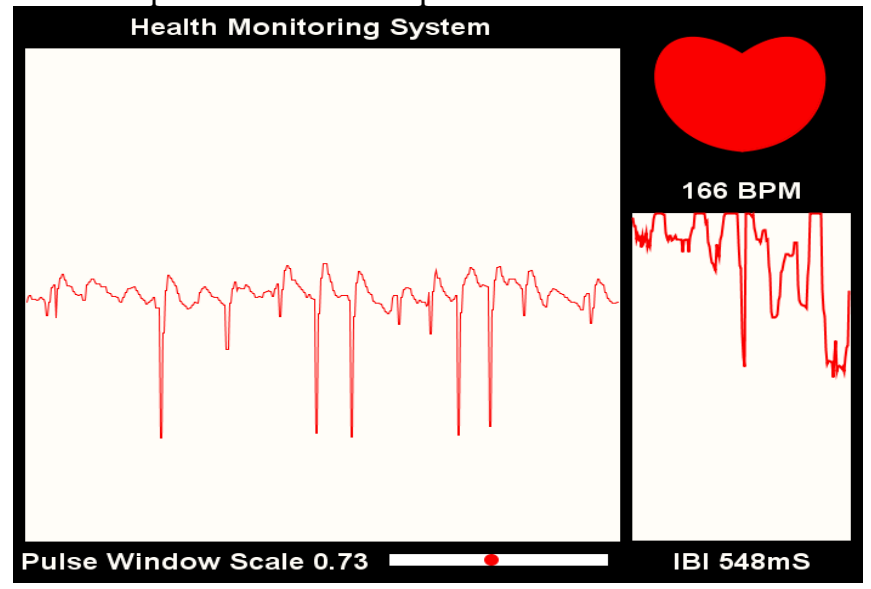

Figure 10 Output Snippet-I

The graphical representation is not possible through Arduino so here used processing IDE so the output will display in graphical manner. It shows the output value and respective graphs.

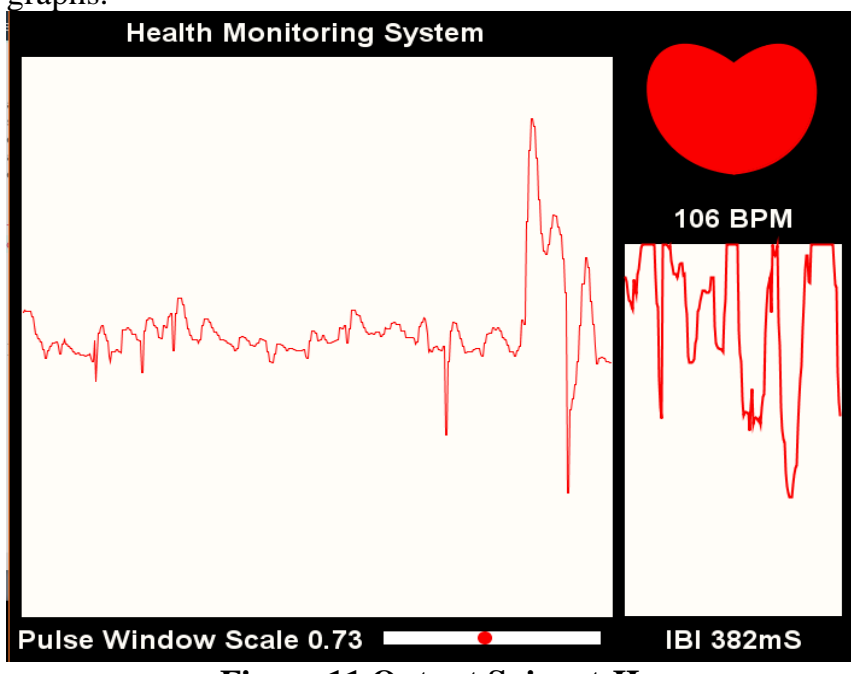

\section{Figure 11 Output Snippet-II}

Above all done through Arduino microcontroller and processing IDE, now the data should be transfer to cloud. So here used ThingSpeak. ThingSpeak ${ }^{\mathrm{TM}}$ is an IoT analytics platform so data getting from Arduino will send to cloud. The API key will generated and after that the access of data transferring is possible.

\section{My Channels}

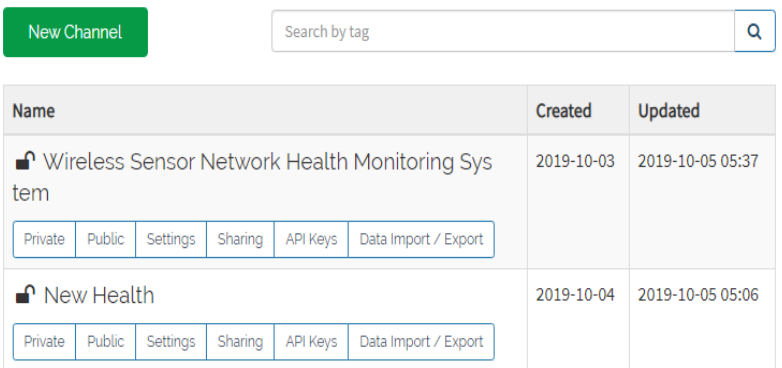

Figure 12 Channel Creation

The very first step is to channel creation, as shown in figure 13. 
Wireless Sensor Network Health Monitoring System

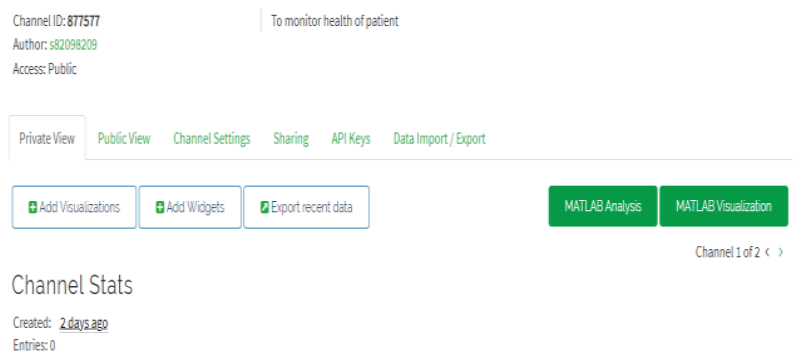

Figure 13 Different Options

After creating channel there have many options such as public view, channel settings, Sharing, API Keys and Data import/Export.

\begin{tabular}{lll|l} 
Private View Public View Channel Settings Sharing & API Keys
\end{tabular}

\section{Write API Key}

Key
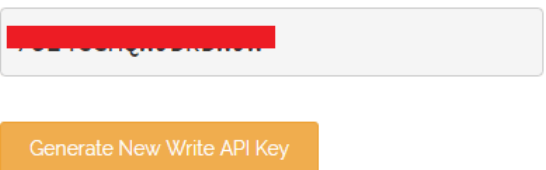

Figure 14 API Key

The API key is used to access ThingSpeak and send data from Arduino to ThingSpeak.

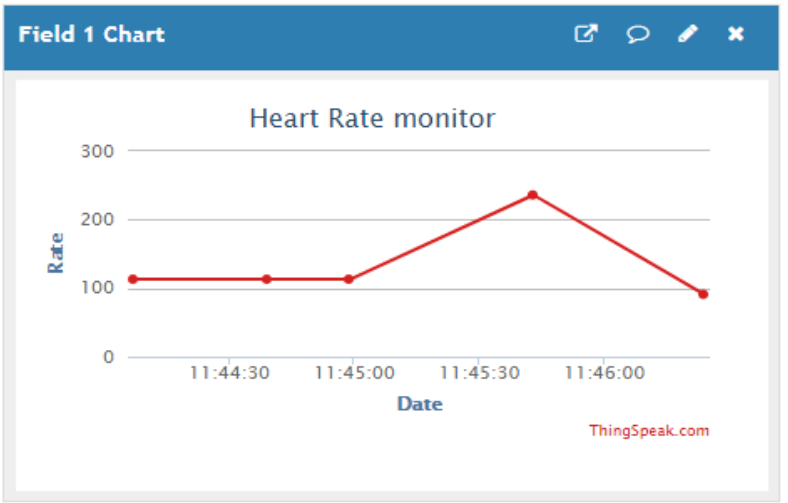

Figure 15 Graphical Representation

Actual live graph of Heart Rate shown in figure 16. This can be available anywhere and anytime.

\section{Table 1 Heart Rate and its causes}

\begin{tabular}{|l|l|l|}
\hline Age & $\begin{array}{c}\text { Estimated maximum } \\
\text { heart rate }\end{array}$ & $\begin{array}{c}\text { Target heart rate (60-85 } \\
\text { percent of max) }\end{array}$ \\
\hline $\mathbf{2 0}$ & 200 & $120-170$ \\
\hline $\mathbf{2 5}$ & 195 & $117-166$ \\
\hline $\mathbf{3 0}$ & 190 & $114-162$ \\
\hline $\mathbf{3 5}$ & 185 & $111-157$ \\
\hline $\mathbf{4 0}$ & 180 & $108-153$ \\
\hline $\mathbf{4 5}$ & 175 & $105-149$ \\
\hline $\mathbf{5 0}$ & 170 & $102-145$ \\
\hline $\mathbf{5 5}$ & 165 & $99-140$ \\
\hline $\mathbf{6 0}$ & 160 & $96-136$ \\
\hline $\mathbf{6 5}$ & 155 & $93-132$ \\
\hline $\mathbf{7 0}$ & 150 & $90-123$ \\
\hline
\end{tabular}

\section{FUTURE SCOPE AND CHALLENGES}

Numerous individual social insurance gadgets utilize diverse remote advances, don't have good interfaces and regularly require link association. Subsequently, it is basic to evacuate wired associations and grow short-go remote associations for plausible availability between gadgets. Zigbee over IEEE
802.15.4 and Bluetooth over IEEE 802.15.1 are the two principle low power utilization remote correspondences that have short range correspondence conventions to supplant links. Bluetooth is a modest gadget for short range correspondence that dependent on a remote radio framework. While work organizing is conceivable, it has principally been utilized for point to point correspondence and to create little impromptu systems. Bluetooth is vigorous, requires low multifaceted nature, low power and ease. Innovative work has made keen brilliant homes offering a solid association with the Internet and cloud administrations, which additionally making locally situated wellbeing checking frameworks. For wellbeing observing and intercession to be really universal and financially savvy, this paper calls for wellbeing checking to be considered as a fundamental piece of any one.

\section{CONCLUSION}

Heartbeat rate monitoring is valuable strategy for checking the heartbeats. IOT concept transit pulse values to cloud. This paper represented the home Pulse rate checking, and has seen that such frameworks would in general be structured in detachment, as their very own major aspect organize, as opposed to part of increasingly dependable home control frameworks. This paper represent the fetching values from sensors attached to human body and send data to cloud. The values can be obtained by doctors from remote place. Represent the graphically manner output for easy to understand.

\section{ACKNOWLEDGMENT}

Dr. Thorat Suryakant, thanks for his guidance and support. I will forever remain grateful for constant support and guidance extended by him, for the completion of paper.

\section{REFERENCES}

1. A Right to Health. Available at http://www.who.int/mediacentre/ factsheets.

2. Abdullah A., Ismael A., Rashid A., ET AL.: 'Real time wireless health monitoring application using mobile devices', Int. J. Comput. Netw. Commun., 2015, 7, (3), pp. 13-30.

3. Sirisha B., Shraddha T., Vijayanand K.: 'Real-time multi-patient monitoring system using ARM and wireless sensor network', Int. J. Commun. Netw. Secur., 2013, 2, (2), pp. 41-47, ISSN: 2231-1882

4. L.in Y.-F., Shie H.-H., Yang Y.-C., ET AL.: 'Design of a real-time and continua-based framework for care guideline recommendations', Int. J. Environ. Res. Public Health, 2014, 11, pp. 4262-4279

5. 5.https://www.healthitoutcomes.com/doc/pros-and-cons-of-remote-patie nt-monitoring-0001

6. Omar S. Alwan, K. Prahald Rao, "Dedicated real-time monitoring system for health care using ZigBee" Published in Healthcare Technology Letters; Received on 29th April 2017; Revised on 30th May 2017; Accepted on 31st May 2017.

7. N. Neha Beri, "Wireless Sensor Network Based Patient Health Care Parameters Monitoring System", International Journal of Engineering Research in Computer Science and Engineering (IJERCSE) Vol 5, Issue 4, April 2018.

8. Ryan Green, Mustafa Asili, and Erdem Topsakal 2013, 'Wireless Smartphone Communication for Medical Telemetry Systems', IEEE Journal of Biomedical And Health Informatics, VOL. 19, NO. 1.

9. Amna Abdullah and Asma Ismael 2015, 'Real Time Wireless Health Monitoring Application Using Mobile Devices', International Journal of Computer Network \& Communications (IJCNC) Vol.7, No.3.

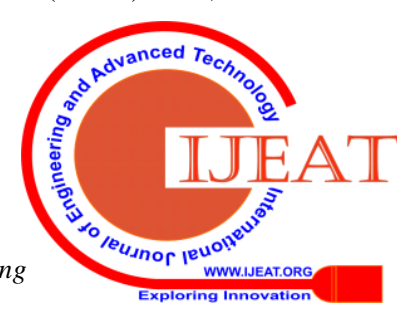


10. Siti Sarah Meskam, Nur Quraisyia Aqilah MohdRusl and Nasiha Sakinah Zamery2013, 'Body Temperature Measurement for Remote Health Monitoring System', Proc. of the IEEE International Conference on Smart Instrumentation, Measurement and Applications (ICSIMA).

11. Parane, K.A, Patil, N.C. Poojara, S.R. and Kamble, T.S 2014, 'Cloud based Intelligent Healthcare Monitoring System', In the proceedings of International Conference on Issues and Challenges in Intelligent Computing Techniques (ICICT), February 7-8, Ghaziabad, Indian, pp. 697-701.

12. Tello, J.P. Manjarres, O. Quijano, and M. Blanco, A. et al 2013 , ‘ Remote Monitoring System of ECG and Human Body Temperature Signals', IEEE Latin American Transaction, Vol. 11, No. 1February, pp. 314-318.

13. Adebayo, Abayomi-Alli \& Ikuomola, Aderonke \& Aliyu, Opeyemi \& Abayomi-Alli, Olusola. (2014). Development of a Mobile Remote Health Monitoring system - MRHMS. African Journal of Computing and Information Communication Technology. 7. 14-22

\section{AUTHORS PROFILE}

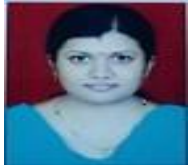

Karhale Deepali B, Research Scholar, School of Computational Sciences, at S. R. T. M. University, Nanded. 02 papers published in International Conferences / Journals.

Dr. Thorat Suryakant Baburao, $\mathrm{PhD}$ (Businesses Management),MBA,PhD(CSE),ME(CSE),M.Sc(Elect), AMIE, Currently working as Director at SSBES'S ITM College, Nanded. Published more than 100 papers in National and International conferences / Journals. 